\title{
HAMBATAN AKSES INFORMASI KESEHATAN REPRODUKSI PADA MAHASISWA KESEHATAN UNIVERSITAS MUHAMMADIYAH SURAKARTA
}

\author{
Izzatul Arifah $^{1 *}$, Meutia Fildzah Sharfina ${ }^{2}$ \\ ${ }^{1,2}$ Program Studi Kesehatan Masyarakat Fakultas Ilmu Kesehatan Universitas \\ Muhammadiyah Surakarta. Jl. A. Yani, Pabelan, Kartasura, Surakarta \\ Email:1ia523@ums.ac.id, ${ }^{2}$ Meutiafildzah@gmail.com
}

\begin{abstract}
Abstrak
Ketersediaan pelayanan dan adanya kebutuhan untuk mengakses informasi saja belum dapat meningkatkan akses jika remaja masih mengalami berbagai hambatan akses. Penelitian bertujuan untuk mengetahui hubungan hambatan akses kognitif dengan akses informasi kesehatan reproduksi pada mahasiswa. Desain penelitian observasional dengan pendekatan cross-sectional. Sampel penelitian adalah mahasiswa fakultas-fakultas kesehatan (FIK Farmasi, kedokteran dan kedokteran gigi) di Universitas Muhammadiyah Surakarta berjumlah 280 responden. Pengambilan sampel menggunakan teknik Proportional Random Sampling. Instrumen penelitian berupa self- administered kuesioner yang sudah diuji validitas dan reliabilitas. Analisis data meliputi analisis bivariabel dengan uji statistik Chi-Square dan analisis multivariabel menggunakan uji regresi logistic dengan dengan tingkat kemaknaan 95\%. Analisis multivariabel menunjukkan terdapat hubungan yang bermakna antara hambatan akses kognitif setelah mempertimbangkan variabel lain yaitu hambatan akses psikososial dan jenis kelamin $(\mathrm{p}<0,050)$. Terdapat kecenderungan responden yang mengakses informasi kesehatan reproduksi lebih tinggi pada kelompok yang tidak mengalami hambatan dibanding yang mengalami hambatan akses kognitif. Ada hubungan yang bermakna antara hambatan akses psikososial dan jenis kelamin dengan akses informasi kesehatan reproduksi. Tidak terdapat hubungan antara tingkat penghasilan orang tua dengan akses informasi kesehatan reproduksi.
\end{abstract}

Kata kunci : Akses informasi kesehatan reproduksi, hambatan akses, hambatan kognitif

\begin{abstract}
Availability of services and the demand to access information alone cannot improve access if adolescents are still experiencing various barriers to access. The study aims to determine the relationship of cognitive barriers to access to reproductive health information. The study design was observational with a cross-sectional approach. The sample was 280 students of health faculties (Pharmacy, Health knowledge, medicine and dentistry) at Muhammadiyah University Surakarta. The samples were taken using Proportional Random Sampling techniques. The research instrument is a self-administered
\end{abstract}


questionnaire that has been tested for validity and reliability. Data analysis included bivariable analysis with Chi-Square statistical tests and multivariable analysis using logistic regression tests with a significance level of $95 \%$. Multivariable analysis showed that there was a significant relationship between cognitivebarriers to access after considering other variables, namely psychosocial barriers and sex ( $\mathrm{p}$ $<0.050$ ). There is a tendency for respondents who access reproductive health information to be higher in groups that do not experience cognitive barriers than those who do experience cognitive barriers. There is a significant relationship between psychosocial barriers and sex with access to reproductive health information. There is no relationship between the income level of parents and access to reproductive health information.

Keywords: Access to reproductive health information, cognitive barriers, access barriers

\section{PENDAHULUAN}

Dua dekade setelah ICPD Cairo 1994, salah satu Progamme of Action (PoA) ICPD yaitu "menyediakan pendidikan dan pelayanan yang dibutuhkan remaja agar memampukan remaja mengatasi masalah seksualitasnya dengan benar dan bertanggung jawab" belum sepenuhnya tercapai di banyak negara termasuk Indonesia (Chandra dkk., 2015). Komitmen pemerintah Indonesia mengenai hal tersebut diwujudkan dalam berbagai program, terutama Pelayanan Kesehatan Peduli Remaja (PKPR) dari Kementrian Kesehatan dan Generasi Berencana (Genre) dengan Pusat Informasi Kesehatan Remaja/Mahasiswa (PIK-R/M) dari BKKBN. PKPR mulai diselenggarakan di Puskesmas sejak tahun 2003. Data menunjukkan pada tahun 2014 baru $81 \%$ kabupaten memiliki setidaknya 4 Puksemas dengan PKPR. Masih jauh dari target tahun 2019 yaitu 45\% Puskemas di Indonesia menyelenggarakan kegiatan kesehatan remaja (Kemenkes, 2015). Ketersediaan pelayanan tersebut saja tidak cukup untuk meningkatkan kesehatan remaja. Remaja perlu dapat menjangkau atau mengakses informasi dan pusat pelayanan kesehatan reproduksi tersebut untuk mendapatkan manfaatnya (Chandra dkk., 2015). Data hasil Survei Demografi Kesehatan Indonesia (SDKI) 2017 menunjukkan baru sekitar 34\% remaja putri yang tahu adanya tempat pelayanan informasi dan konseling kesehatan reproduksi berupa PKPR dan hanya $16 \%$ remaja putri yang mengetahui tentang PIK-R/M tersebut sehingga aksesnya dapat diasumsikan lebih kecil lagi (BPS, 2018). Sebagaimana hasil penelitian Nurmansyah dkk. (2013) dari $15,4 \%$ remaja yang mengetahui lembaga yang fokus pada kesehatan reproduksi hanya $4,4 \%$ remaja yang telah mengunjunginya.

Ketidaktahuan tentang pusat pelayanan tersebut dapat menjadi penyebab kurangnya pengetahuan remaja tentang kesehatan reproduksi. Data SDKI tahun 2017 menunjukkan remaja putri usia 15-19 tahun yang memiliki pengetahuan yang memadai tentang kesehatan reproduksi hanya sebesar 33\% pada remaja wanita dan $37 \%$ pada remaja pria (BPS, 2018). Padahal pengetahuan yang memadai tentang kesehatan reproduksi dan seksual yang komprehensif secara langsung maupun tidak langsung mencegah berbagai dampak buruk kesehatan reproduksi remaja. Data 
menunjukkan remaja menyumbang $30 \%$ dari keseluruhan beban penyakit (Disability-adjusted life years) karena kehamilan remaja dikaitkan dengan peningkatan aborsi tidak aman, persalinan dengan penyulit, kematian ibu, BBLR dan kematian anak (Chandra dkk., 2015). Sementara itu angka fertilitas kelompok usia 15-19 tahun di Indonesia menunjukkan penurunan yang tidak signifikan selama 5 tahun terakhir yaitu 48 per 1000 perempuan (Kemenkes, 2015). Banyak remaja di Indonesia sudah mulai terlibat pada aktivitas seksual. Hasil SDKI 2017 memaparkan fakta bahwa 8\% remaja pria dan $2 \%$ remaja wanita di Indonesia pernah melakukan hubungan seksual pranikah. Berdasarkan umur, data menunjukkan bahwa remaja pria usia 2024 tahun persentasenya lebih tinggi yang melaporkan pengalaman seksual pranikah dibandingkan usia 15-19 yaitu $14 \%$ dibanding 4\%. Hal tersebut menunjukkan bahwa informasi kesehatan reproduksi pada usia remaja akhir (20-24 tahun) masih penting untuk diberikan. Mengingat bahwa sebagian besar fokus program Kesehatan Reproduksi Remaja adalah pada remaja 15-19 tahun.

Untuk dapat memiliki pengetahuan tentang kesehatan reproduksi yang mumpuni serta berlaku yang terlindung dari risiko masalah kesehatan reproduksi, remaja perlu dapat mengakses informasi dan pusat pelayanan kesehatan reproduksi yang tersedia (Chandra dkk., 2015). Sementara itu pengetahuan tentang akses informasi kesehatan reproduksi pada remaja dan faktor-faktor yang mempengaruhinya di Indonesia masih terbatas. Beberapa faktor yang diketahui mempengaruhi diantaranya yaitu keahlian komunikasi interpersonal dan keterpercayaan tenaga kesehatan dan persepsi tidak membutuhkan informasi/pelayanan (Coker dkk., 2010). Bahkan jika remaja merasa membutuhkan informasi dan layanan banyak faktor dapat menghambat akses sehingga remaja batal mengakses sumber informasi dan pelayanan tersebut (Perry dkk., 2012). Faktor tersebut meliputi ketidaktahuan keberadaan pusat informasi pelayanan kesehatan reproduksi (hambatan kognitif), perasaan takut dan malu mendatangitempat tersebut (hambatan psikososial), hambatan struktural seperti waktu jam buka, waktu tunggu pelayanan, serta biaya pelayanan (hambatan ekonomi) (Perry dkk., 2012, Bankole dan Malancer, 2010).

Pengetahuan tentang sumber informasi dan pelayanan kesehatan reproduksi dapat menjadi titik masuk yang penting remaja bagi remaja untuk mengakses informasi, konseling dan pelayanan (Alli dkk., 2013). Oleh karena itu peneliti tertarik untuk melakukan penelitian untuk menganalisis hubungan hambatan akses kognitif dengan akses informasi kesehatan reproduksi khususnya pada mahasiswa fakultas kesehatan. Selain itu peneliti menentukan lokasi di Universitas Muhammadiyah Surakarta dikarenakan universitas ini belum memiliki pusat informasi dan layanan yang bergerak dibidang informasi kesehatan reproduksi. Pengkhususan penelitian pada mahasiswa kesehatan tadi dikaitkan dengan alasan bahwa mahasiswa kesehatan sudah terpapar informasi tentang kesehatan reproduksi pada proses pembelajaran, yang diasumsikan memiliki cukup pengetahuan tentang kesehatan reproduksi sehingga akan menimbulkan demand untuk mengakses informasi kesehatan reproduksi lebih lanjut.

\section{METODE PENELITIAN}

Penelitian merupakan penelitian kuantitatif dengan desain penelitian observasional pendekatan cross-sectional. Penelitian ini dilakukan pada bulan Oktober 2018 di wilayah Universitas Muhammadiyah Surakarta yaitu di 
Fakultas Ilmu Kesehatan, Fakultas Farmasi, Fakultas Kedokteran, dan Fakultas Kedokteran Gigi. Populasi penelitian adalah mahasiswa angkatan tahun 2015 Fakultas Ilmu Kesehatan, Fakultas Farmasi, Fakultas Kedokteran, dan Fakultas Kedokteran Gigi pada di Universitas Muhammadiyah Surakarta berjumlah 1.283 mahasiswa. Sampel penelitian berjumlah 280 responden. Penentuan besar sampel tersebut menggunakan rumus Lemeshow dan jumlah sampel yang didapat melebihi dari jumlah sampel minimal. Pengambilan sampel menggunakan teknik Proportional Random Sampling. Variabel bebas adalah hambatan akses (hambatan kognitif dan hambatan psikologis). Variabel terikat adalah akses informasi kesehatan reproduksi yang didefinisikan sebagai akses responden mendapatkan informasi kesehatan reproduksi melalui tenaga kesehatan. Variabel luar adalah faktor permintaan (jenis kelamin dan tingkat penghasilan orang tua). Instrumen penelitian berupa self- administered kuesioner yang sudah diuji validitas dan reliabilitas. Analisis data meliputi analisis bivariabel menggunakan uji statistik ChiSquare dan analisis multivariabel menggunakan uji regresi logistic dengan dengan kemaknaan $95 \%$.

\section{HASIL DAN PEMBAHASAN}

\section{Karakteristik Responden}

Pengolahan data karakteristik responden berdasarkan jenis kelamin, umur dan tingkat penghasilan orang tua menunjukkan bahwa lebih dari tiga perempat responden merupakan perempuan. Mayoritas responden berusia 21 tahun. Tingkat penghasilan orang tua sebagian besar merupakan pada kelompok penghasilan tinggi. Lebih dari sepertiga responden mengalami hambatan kognitif dan hambatan psikologis. Perhatian lebih lanjut ditujukan pada hambatan kognitif.
Karena responden adalah mahasiswa fakultas-fakultas kesehatan sehingga disayangkan masih terdapat responden yang tidak mengetahui fasilitas yang menyediakan informasi kesehatan reproduksi terpercaya.

Tabel 1. Karakteristik Responden

\begin{tabular}{|c|c|c|}
\hline Variabel & Frekuensi & $\begin{array}{c}\text { Persentase } \\
(\%)\end{array}$ \\
\hline \multicolumn{3}{|l|}{ Jenis Kelamin } \\
\hline Laki-laki & 56 & 20 \\
\hline Perempuan & 224 & 80 \\
\hline \multicolumn{3}{|l|}{ Umur } \\
\hline 20 & 72 & 25.7 \\
\hline 21 & 167 & 59.6 \\
\hline 22 & 34 & 12.1 \\
\hline 23 & 5 & 1.8 \\
\hline 24 & 2 & 0.7 \\
\hline \multicolumn{3}{|l|}{ Tingkat } \\
\hline Penghasilan Orang & 103 & 36.7 \\
\hline Tua $^{\mathrm{a}}$ & 177 & 63.2 \\
\hline \multicolumn{3}{|l|}{ Rendah } \\
\hline \multicolumn{3}{|l|}{ Tinggi } \\
\hline \multicolumn{3}{|l|}{ Hambatan Kognitif $^{\text {b }}$} \\
\hline Tidak Mengalami & 111 & 60.4 \\
\hline Mengalami & 169 & 39.6 \\
\hline \multicolumn{3}{|l|}{ Hambatan } \\
\hline Psikososial $^{\mathrm{c}}$ & 193 & 68.9 \\
\hline $\begin{array}{l}\text { Tidak Mengalami } \\
\text { Mengalami }\end{array}$ & 87 & 31.1 \\
\hline
\end{tabular}

Sumber : Pengolahan data primer

Keterangan:

a Tingkat Penghasilan merupakan proxy dari tingkat ekonomi keluarga: Rendah (13 juta), tinggi (>3 juta); ${ }^{\mathrm{b}}$ Hambatan Kognitif merupakan pengetahuan tentang fasilitas kesehatan yang menyediakan informasi terpercaya tentang kesehaatn reproduksi; c Hambatan Psikososial merupakan perasaan takut yang dilaporkan responden saat mencari informasi kesehatan reproduksi.

\section{Analisis hubungan hambatan akses, Hambatan Psikososial dan Akses Informasi Kesehatan Reproduksi}

Hasil tabulasi silang (Tabel 2) menunjukkan kecenderungan responden yang mengakses informasi kesehatan reproduksi lebih tinggi pada kelompok yang tidak mengalami hambatan dibanding yang mengalami hambatan 
akses kognitif. Hal tersebut didukung dengan data OR yang menunjukkan adanya peningkatan resiko $80 \%$ pada yang tidak mengalami hambatan akses kognitif. Hasil uji statistik menyatakan hubungan bermakna antara hambatan kognitif dengan akses informasi kesehatan reproduksi. Variabel lain yang juga memiliki hubungan yang bermakna secara statistik dengan akses informasi kesehatan reproduksi yaitu hambatan psikososial dan jenis kelamin. Sedangkan tingkat penghasilan orang tua sebagai proxy tingkat ekonomi tidak menunjukkan hubungan bermakna.

Tabel 2. Hasil Analisis Chi Square Variabel Hambatan Akses Kognitif, Hambatan

Akses Psikososial, jenis kelamin dan tingkat pengasilan orang tua terhadap Akses Informasi Kesehatan Reproduksi

\begin{tabular}{|c|c|c|c|c|c|c|c|}
\hline \multirow{3}{*}{ Variabel } & \multicolumn{4}{|c|}{$\begin{array}{c}\text { Akses Informasi Kesehatan } \\
\text { Reproduksi }\end{array}$} & \multirow{3}{*}{ P-value } & \multirow{3}{*}{$O R$} & \multirow{3}{*}{ CI 95\% } \\
\hline & \multicolumn{2}{|c|}{ Mengakses } & \multicolumn{2}{|c|}{$\begin{array}{c}\text { Tidak } \\
\text { Mengakses }\end{array}$} & & & \\
\hline & (n) & $\%$ & (n) & $\%$ & & & \\
\hline Hambatan Akses kognitif & & & & & 0.015 & & \\
\hline Tidak mengalami & 67 & 60.4 & 44 & 39.6 & & 1.8 & $1.11-2.95$ \\
\hline Mengalami Ref & 77 & 45.6 & 92 & 54.4 & & & \\
\hline Hambatan Akses Psikosial & & & & & 0.024 & & \\
\hline Tidak mengalami & 108 & 56.0 & 85 & 44.0 & & 1.8 & $1.07-3.01$ \\
\hline Mengalami ${ }^{\text {Ref }}$ & 36 & 41.4 & 51 & 58.6 & & & \\
\hline Jenis Kelamin & & & & & 0.001 & & \\
\hline Perempuan & 126 & 56.5 & 97 & 43.5 & & 2.8 & $1.51-5.22$ \\
\hline Laki-laki $^{\text {Ref }}$ & 18 & 31.6 & 39 & 68.4 & & & \\
\hline Tingkat Penghasilan Orang & & & & & 0.461 & & \\
\hline Tua & & & & & & & \\
\hline Rendah $^{\text {Ref }}$ & 50 & 48.5 & 53 & 51.5 & & & \\
\hline Tinggi & 94 & 53.1 & 83 & 46.9 & & 1.2 & $0.73-1.95$ \\
\hline
\end{tabular}

Sumber:Pengolahan Data Primer

Berdasarkan hasil analisis bivariabel, variabel yang bisa dimasukkan kedalam model regresi logistik adalah variabel hambatan kognitif, hambatan psikososial dan jenis kelamin. Kemudian dibangun beberapa model regresi logistik untuk mengamati perubahan dari OR Crude dan OR Adjusted pada variable yang teliti. Model akhir ditunjukkan pada Tabel 3. Model tersebut menunjukkan tidak terdapat perubahan OR yang signifikan variabel utama penelitian.
Tabel 3. Hasil Analisis Regresi Logistik Variabel Hambatan Akses Kognitif, Hambatan Akses Psikososial, jenis kelamin terhadap Akses Informasi Kesehatan Reproduksi

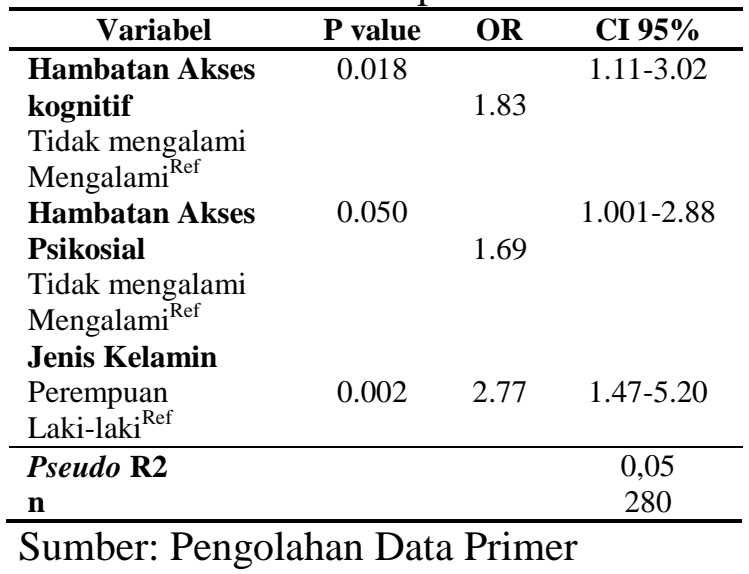


Model ini menunjukkan bahwa hambatan kognitif berhubungan secara bermakna dengan akses informasi kesehatan reproduksi setelah mempertimbangkan variabel lain yaitu hambatan psikososial dan jenis kelamin. Hal ini menunjukkan bahwa responden yang tidak mengalami hambatan kognitif kecenderungannya untuk mengakses informasi kesehatan reproduksi $83 \%$ lebih tinggi jika kondisi variabel lain yaitu hambatan psikosial dan jenis kelaminnya sama. Variabel hambatan psikososial dan jenis kelamin juga mempunyai hubungan yang signifikan secara statistik dengan akses informasi kesehatan reproduksi. Kualitas model ini dalam memprediksi akses informasi kesehatan reproduksi dijelaskan melalui nilai pseudo R2 yaitu 0,05 . Hal tersebut berarti bahwa 5\% variasi pada akses informasi kesehatan reproduksi ini dapat dijelaskan oleh model ini. Sedangkan $95 \%$ sisanya dipengaruhi oleh faktor risiko lain yang tidak terjaring dalam penelitian ini. Akan tetapi berdasarkan analisis Goodness of fits test hasil p-value sebesar 0,53 $(>0,05)$ dapat disimpulkan bahwa persamaan model ini memiliki kaliberasi yang baik, dan dapat memberikan prediksi yang benar tentang akses informasi kesehatan reproduksi.

Secara umum penelitian ini menunjukkan bahwa hambatan akses kognitif berhubungan dengan akses informasi kesehatan reproduksi dengan mempertimbangkan variabel-variabel lain. Kelompok mahasiswa yang tidak mengalami hambatan akses kognitif (mengetahui keberadaan pusat informasi dan pelayanan kesehatan reproduksi) memiliki kecenderungan untuk melakukan akses informasi kesehatan reproduksi. Faktor yang turut berhubungan dengan akses informasi kesehatan reproduksi adalah hambatan psikososial dan jenis kelamin. Kelompok responden yang mengalami hambatan psikososial (merasa takut untuk mengakses informasi kesehatan reproduksi) cenderung tidak mengakses informasi kesehatan reproduksi, serta jenis kelamin laki-laki juga cenderung untuk tidak mengakses informasi kesehatan reproduksi.

Hasil studi telaah pustaka Price dkk. (2007) menunjukkan faktor-faktor yang mempengaruhi akses yaitu: ketersediaan, keterjangkauan, penerimaan, kenyamanan dan pengetahuan. Hambatan akses kognitif dapat menunjukkan adanya ketidaktahuan tentang ketersediaan suatu sumber pelayanan kesehatan. Pengetahuan tentang keberadaan suatu pusat informasi/pelayanan kesehatan reproduksi berhubungan dengan akses informasi kesehatan reproduksi. Salah satu alasan remaja tidak mendatangi pusat informasi dan pelayanan kesehatan reproduksi adalah tidak mengetahui keberadaan tempat tersebut (Alli dkk., 2013). Pada mahasiswa yang mengetahui tempat layanan tersebut tidak semua mahasiswa mendatangi tempat tersebut untuk berkonsultasi (Nurmansyah dkk., 2013). Temuan penting penelitian ini menunjukkan bahwa pada kelompok responden yang mengetahui pusat informasi/layanan kesehatan reproduksi, hanya $44 \%$ yang pernah datang ke tempat tersebut. Selain itu pengetahuan tentang program kesehatan reproduksi juga masih rendah. Temuan penelitian menunjukkan sebesar $25 \%$ mahasiswa mengetahui tentang PKPR dan 45\% mengetahui tentang Genre (PIK-R/M). Hal tersebut menunjukkan kurang dari separuh responden mengetahui tentang program yang berkaitan dengan kesehatan reproduksi remaja, padahal responden merupakan mahasiswa kesehatan yang sudah pernah terpapar dengan berbagai informasi tentang program kesehatan. Namun peneliti tidak melakukan penelitian lebih lanjut tentang kurikulum pendidikan yang berkaitan dengan program dan informasi kesehatan reproduksi yang diperoleh selama masa 
pendidikan, sehingga ini merupakan keterbatasan penelitian ini. Hal ini juga menekankan pentingnya untuk melakukan penelitian yang sama dengan responden yang lebih luas yaitu pada semua fakultas baik kesehatan maupun non-kesehatan.

Selain akibat kekurangtahuan tentang ketersediaan pelayanan kesehatan, penyebab mahasiswa tidak mengakses pusat informasi kesehatan tersebut adalah akibat menganggap hal tersebut tidak perlu dilakukan (Coker dkk., 2010). Penelitian Zainafree (2015) pada mahasiswa UNNES menunjukkan mahasiswa yang memiliki perilaku berisiko cenderung menilai bahwa layanan kesehatan reproduksi remaja tidak penting karena mahasiswa bisa mengakses informasi secara bebas melalui media massa maupun internet sehingga hal itu menjadi salah satu hambatan akses dan informasi mengenai seksualitas dan kesehatan reproduksi bagi remaja melalui tenaga kesehatan. Hal tersebut menunjukkan urgensi untuk melakukan penelitian tentang akses informasi kesehatan reproduksi pada fakultas nonkesehatan beserta faktor-faktor yang dapat mempengaruhinya. Untuk dapat meningkatkan pemahaman tentang akses informasi kesehatan reproduksi pada mahasiswa umumnya yang tidak sering terpapar informasi mengenai kesehatan.

Untuk mengatasi hambatan akses kognitif tersebut terdapat beberapa pilihan intervensi yang dapat dipilih. Kesterton dan Mello (2010) menunjukkan berdasarkan temuan studi review sistematis, menyatakan terdapat beberapa intervensi yang efektif untuk meningkatkan akses remaja pada pusat informasi/pelayanan kesehatan reproduksi remaja. Salah satunya yaitu dengan menghubungkan pusat pelayanan tersebut dengan program pendidikan di lembaga pendidikan. Penghubung tersebut dapat berupa sistem rujukan antara pelayanan kesehatan dengan lembaga pendidikan.
Sehingga dapat mengurangi berbagai hambatan akses yang dapat muncul jika berfokus pada pusat informasi dan pelayanan dengan tenaga kesehatan atau di fasilitas kesehatan.

Hambatan psikosial dapat menunjukkan adanya hambatan pada penerimaan sumber pelayanan kesehatan. Budaya juga menyebabkan remaja kesulitan secara terbuka mendapatkan pengetahuan mengenai seksualitas dan reproduksi. Stigma sosial berupa tabu dalam membicarakan seksualitas dan kesehatan reproduksi membatasi ruang pendidikan dan sosial untuk memberikan pengetahuan pada remaja mengenai hal tersebut. Penelitian menunjukkan alasan remaja tidak mendatangi pusat informasi/ konseling adalah dikarenakan merasa malu dan tidak percaya diri dan tidak dapat mempercayai tenaga kesehatan untuk dapat bercerita tentang masalah kesehatan reproduksinya (Agampodi dkk., 2008). Penelitian tentang peta pencarian informasi kesehatan reproduksi pada remaja mengonkonfirmasi bahwa remaja perempuan lebih mengutamakan untuk berdiskusi dengan ibu maupun teman sebagai pilihan pertama untuk berdiskusi jika mengalami masalah kesehatan reproduksi, kemudian dikonfirmasi dari media informasi seperti internet. Sementara untuk remaja putra menjadikan media informasi internet sebagai sumber utama, kemudian sumber informasi dari teman kemudian guru. Alasan penggunaan media internet sebagai rujukan adalah melalui media internet remaja putra lebih bebas untuk mengakses informasi yang dianggap tabu atau sensitif seperti masalah kesehatan reproduksi (Kurniasi dan Komariah, 2017). Penyediaan pusat informasi dan pelayanan kesehatan reproduksi yang ramah remaja di fasilitas kesehatan merupakan suatu intervensi baru terutama di negara berkembang seperti Indonesia (Alli dkk., 2013). Oleh karena itu diperlukan berbagai kajian 
untuk dapat mengetahui efektifitasnya serta permasalahan yang dihadapi dalam pelaksanaannya.

Temuan studi review sistematis Chandra dkk. (2015) menunjukkan bahwa salah satu intervensi yang efektif untuk mengurangi hambatan psikososial adalah dengan melakukan pelatihan pada tenaga kesehatan agar lebih ramah, tidak menghakimi dan lebih menarik minat remaja untuk datang pada pusat informasi dan pelayanan kesehatan reproduksi. Bersamaan dengan itu juga dilaksanakan penggalangan dukungan dan sosialisasi pada anggota masyarakat agar mendukung remaja untuk menggunakan sumber informasi dan pelayanan tersebut.

Hasil penelitian ini menunjukkan jenis kelamin memiliki hubungan yang paling kuat yang menentukkan akses informasi kesehatan reproduksi. Akses informasi kesehatan reproduksi cenderung lebih banyak dilakukan oleh remaja putri dibanding putra. Sebuah studi kualitatif di Sri Lanka menunjukkan bahwa pemuda cenderung tidak menyadari ketersediaan pusat informasi/pelayanan kesehatan reproduksi. Selain itu pemuda juga tidak menyukai berbagi cerita tentang kesehatan reproduksi mereka kepada siapapun. Alasan utamanya adalah pemuda menganggap bahwa mendatangi suatu pusat informasi/konseling akan mengakibatkan mereka dipinggirkan dari kelompok sebayanya. Serta jika remaja putra berbagi cerita tentang masalah kesehatan reproduksi kepada orang tua sebagian besar merasa takut akan dicurigai memiliki masalah (Agampodi dkk., 2008). Keterbatasan lain yang mempengaruhi akses remaja pria merupakan aspek kenyamanan dalam mengakses informasi kesehatan reproduksi. Studi kualitatif oleh Alli dkk. (2013) tentang aspek hubungan tenaga kesehatan dan klien yang berhubungan dengan akses pada pelayanan kesehatan adalah kenyamanan dalam berinteraksi.
Remaja wanita pada umumnya merasa lebih nyaman dengan tenaga kesehatan perempuan, begitu pula sebaliknya jika remaja laki-laki. Hal ini berhubungan dengan kebanyakan pengelola pelayanan kesehatan reproduksi di Indonesia adalah perempuan. Penelitian Arfianti dkk. (2017) di Puskesmas Kota Banda Aceh menunjukkan karakteristik pengelola pelayanan kesehatan reproduksi yang menjadi petugas PKPR kesemuanya adalah perempuan. Maka dalam hal akses tentang informasi dan pelayanan kesehatan reproduksi, remaja pria dapat dianggap sebagai salah satu kelompok yang rentan untuk mengalami masalah akibat kurangnya informasi tersebut, serta memerlukan pendekatan yang berbeda.

\section{KESIMPULAN}

Terdapat hubungan yang bermakna antara hambatan akses kognitif setelah mempertimbangkan variabel lain yaitu hambatan akses psikososial dan jenis kelamin $\quad(p<0,050)$ Terdapat kecenderungan responden yang mengakses informasi kesehatan reproduksi lebih tinggi pada kelompok yang tidak mengalami hambatan dibanding yang mengalami hambatan akses kognitif. Ada hubungan yang bermakna antara hambatan akses psikososial dan jenis kelamin dengan akses informasi kesehatan reproduksi. Tidak terdapat hubungan antara tingkat penghasilan orang tua dengan akses informasi kesehatan reproduksi. Penelitian ini dapat menjadi landasan untuk melakukan intervensi atau perbaikan program kesehatan reproduksi yang sudah ada untuk mengurangi hambatan kognitif dan psikososial yang dialami oleh mahasiswa khususnya untuk remaja lakilaki dalam upaya untuk meningkatkan akses mahasiswa pada informasi kesehatan reproduksi. Selain itu perlu dilakukan penelitian serupatentang akses 
informasi kesehatan reproduksi pada fakultas kesehatan dan non-kesehatan serta mengkaji hambatan-hambatan yang dialami.

\section{DAFTAR PUSTAKA}

Agampodi, S. B., Agampodi, T. C., \& Piyaseeli, U. K. D. (2008). Adolescents perception of reproductive health care services in Sri Lanka. BMC health services research, 8(1), 98.

Alli, F., Maharaj, P., \& Vawda, M. Y. (2013). Interpersonal relations between health care workers and young clients: barriers to accessing sexual and reproductive health care. Journal of community health, 38(1), 150-155.

Arfianti, N., Mudatsir., \& Tahlil, T. (2017). Analisis Implementasi Program Pelayanan Kesehatan Peduli Remaja (PKPR). Jurnal Ilmu Keperawatan. 5:2 ISSN: 23386371.

Bankole, A., \& Malarcher, S. (2010). Removing barriers to adolescents' access to contraceptive information and services. Studies in family planning, 41(2), 117124.

BPS. (2018). Survey Demografi Kesehatan Indonesia 2012. Badan Pusat Statistik, Jakarta.

Chandra-Mouli, V., Svanemyr, J., Amin, A., Fogstad, H., Say, L., Girard, F., \& Temmerman, M. (2015). Twenty years after International Conference on Population and Development: where are we with adolescent sexual and reproductive health and rights?. Journal of Adolescent Health, 56(1), S1-S6.

Chandra-Mouli, V., Lane, C., \& Wong, S. (2015). What does not work in adolescent sexual and reproductive health: a review of evidence on interventions commonly accepted as best practices. Global Health: Science and Practice, 3(3), 333-340.

Coker, T. R., Sareen, H. G., Chung, P. J., Kennedy, D. P., Weidmer, B. A., \& Schuster, M. A. (2010). Improving access to and utilization of adolescent preventive health care: the perspectives of adolescents and parents. Journal of Adolescent Health, 47(2), 133-142.

Kementerian Kesehatan RI. (2015). Infodatin Pusat Data Informasi Kementerian Kesehatan RI Indonesia Situasi Kesehatan Reproduksi Remaja.

Kesterton, A. J., \& de Mello, M. C. (2010). Generating demand and community support for sexual and reproductive health services for young people: A review of the Literature and Programs. Reproductive health, 7(1), 25.

Kurniasih, N., \& Komariah, N. (2017). Peta Pencarian Informasi Kesehatan Reproduksi Remaja Kota Bandung Berdasarkan Jenis Kelamin, Latar Belakang Pendidikan, Status Sosial dan Ekonomi. INA-Rxiv. November 3. doi:10.31227/osf.io/z7kuj.

Nurmansyah, M. I., Al-Aufa, B., \& Amran, Y. (2012). Peran Keluarga, Masyarakat dan Media Sebagai Sumber Informasi Kesehatan Reproduksi pada Mahasiswa. Jurnal Kesehatan Reproduksi, 3(1 Apr), 16-23.

Perry, R. C., Kayekjian, K. C., Braun, R. A., Cantu, M., Sheoran, B., \& Chung, P. J. (2012). Adolescents' perspectives on the use of a text messaging service for preventive sexual health promotion. Journal of Adolescent Health, 51(3), 220225. 
Price, N. L., \& Hawkins, K. (2007). A conceptual framework for the social analysis of reproductive health. Journal of health, population, and nutrition, 25(1), 24.

Zainafree, I. (2015). Perilaku Seksual dan Implikasinya Terhadap Kebutuhan Layanan Kesehatan Reproduksi Remaja di Lingkungan Kampus (Studi Kasus Pada Mahasiswa Universitas Negeri Semarang). Unnes Journal of Public Health, 4(3). 